$P$ a g e | 708

\title{
IDE-IDE PEMIKIRAN PENDIDIKAN SYEKH NAWAWI AL-BANTANI DAN RELEVANSINYA TERHADAPA PENDIDIKAN DI ERA MODERN
}

\author{
Oleh: \\ Deri Yatus Salihin \\ Email; Deriyatussolihin_859@yahoo.com \\ UIN Sunan Kalijaga Yogyakarta
}

\begin{abstract}
Abstrak
Indonesia adalah salah satu Negara yang mayoritas penduduknya beragama Islam, semua itu tidak lepas dari peran ulama-ulama terdahulu yang giat menyebarkan agama Islam, diantara ulama-ulama tersebut ada satu sosok ulama yang luar biasa, yaitu Syekh Nawawi Al-Bantani yang merupakan sosok ulama multidimensional dengan latar belakang pendidikan pesantren. Nama beliau sudah sangat di kenal baik di kalangan akademisi maupun praktisi pendidikan Islam di seluruh penjuru dunia. Melalui karya-karya dan pemikirannya yang monumental, beliau telah memberikan pengaruh dalam berbagai bidang keilmuan meliputi bidang Tafsir, Tauhid, Fiqh, Tasawuf, Sejarah Nabi serta Bahasa dan Retorika. Karya-karya beliau memberikan sumbangan yang sangat besar dalam kemajuan Islam di Indonesia, dan Sampai sekarang, karya-karya Syekh Nawawi masih terus dikaji dan diajarkan sehingga memberikan pengetahuan tentang ajaran Islam yang menyejukkan umat serta beliau salah satu tokoh yang memberikan kontribusi dalam mengIslamkan Indonesia.
\end{abstract}

Keyword: Relevansi, Pendidikan, Era-Modern

\section{A. Sketsa Biografi Syekh Nawawi Al-Bantani}

Seorang Ulama yang paling tersohor dan dikenal terutama dikalangan para santri dan ulama Indonesia, dengan sebutan Syekh Nawawi Al-Bantani. Beliau lahir di kampung Tanara, kecamatan Tirtayasa, Kabupaten Serang, Keresidenan Banten pada tahun 1813M / 1213H. ${ }^{1}$ Ulama Indonesia ini bernama lengkap Muhammad

1 Suwito dan Fauzan, Sejarah Pemikiran Para Tokoh Pendidikan, (Bandung: Angkasa, 2003), hal.289-290

AL-IKHTIBAR (Jurnal Ilmu Pendidikan) Vol. 5 No. 2 Tahun 2018 
Nawawi bin Umar bin 'Arabi. Beliau dikenal juga dengan sebutan Abu Abdul Mut'hi sebagai julukan nama dari anak laki-laki satu-satunya. Dalam kapasitas keulamaanya, beliau dikenal dengan sebutan Muhammad Nawawi Al-Syekh Al-Jawi Al-Bantani. ${ }^{2}$

Secara silsislah Nawawi merupakan keturunan ke-12 dari Maulana Syarif Hidayatullah (Sunan Gunung Jati Cirebon), yaitu keturunan dari putra Maulana Hasanuddin (Sultan Banten 1) yang bernama Sunyararas (Tajul 'Arsy). ${ }^{3}$ Nasabnya bersambung dengan Nabi Muhammad SAW melalui ayahnya K.H. Umar dan ibunya Zubaidah. Untuk jelasnya silsilah Syekh Nawawi dari garis ayahnya sebagai berikut: Syekh Nawawi bin Kyai Umar bin Kyai Arabi bin Kyai Ali bin Kyai Jamad bin Ki Janta bin ki Masbugil bin ki Masqun bin Ki Masnun bin Ki maswi bin Ki Tajul Arusy tanara bin Maulana Hasanuddin Banten bin maulana Syarif Hidayatullah Cirebon bin Raja Amatudin Abdullah bin Ali Nuruddin bin Maulana Jamaluddin Akbar Husain bin Imam Sayyid Ahmad Syah Jalal bin Abdullah Adzmah Khan bin Amir Abdullah Malik bin Sayyid Alwi bin Sayyid MuhammadShahib Mirbath bin Sayyid Ali Khali' Qasim bin Sayyid Alwi bin Imam Ubaidillah bin Imam Ahmad Muhajir Ilallahi bin Imam Isa An-Naqib bin Imam Muhammad Naqib bin Imam Ali Aridhi bin Imam Ja'far Ash-Shaddiq bin Imam Muhammad Al-Baqir bin Imam Ali Zainal Abidin bin Sayyiduna Husain bin Sayyidatuna Fathimah Zahra binti Muhammad Rasulullah SAW dan Silsilah dari garis ibunya adalah Syekh Nawawi bin Nyi Zubaidah binti Muhammad Singaraja. ${ }^{4}$

Sejak kecil syekh Nawawi telah diarahkan ayahnya, K.H. Umar bin Arabi yang merupakan seorang pejabat penghulu yang memimpin masjid untuk menjadi seorang ulama, sudah terlihat kecerdasan beliau dimana pada usia 5 tahun Syekh Nawawi dengan mudahnya menerima pelajaran yang telah di berikan ayahnya,

${ }^{2}$ Maragustam, Pemikiran Pendidikan Syekh Nawawi Al-Bantani, (Yogyakarta: Data Media,2007), hal.100

${ }^{3}$ Salman Iskandar, 55 Tokoh Muslim Indonesia Paling Berpengaruh, ( Solo: Tiga Serangkai, 2011), hal.63

${ }^{4}$ Maragustam, Pemikiran Pendidikan Syekh Nawawi Al-Bantani,...,hal. 100-101

AL-IKHTIBAR (Jurnal Ilmu Pendidikan) Vol. 5 No. 2 Tahun 2018 
beberapa pertanyaan kritispun sering iya lontarkan yang terkadang membuat ayahnya bingung, dengan melihat potensi yang ada pada diri anaknya sehingga K.H Umar menyerahkan putranya kepada K.H Sahal yang merupakan Ulama terkenal di Banten, setelah belajar dengan K.H Sahal, Nawawi melanjutkan pendidikannya kepada K.H. Yusuf yang merupakan ulama besar Purwakarta. ${ }^{5}$

Dengan kecintaan syekh Nawawi terhadap Ilmu Agama membuat dirinya bersemangat untuk selalu mempelajari berbagai macam jenis ilmu agama, dalam menuntut ilmu, Imam Nawawi kelihatanya sangat terpengaruh dengan pernyataan Imam Safi'i dalam mendorong pencarian Ilmu kepada murid-muridnya. " Tidaklah layak bagi seseorang yang berakal dan berilmu beristirahat dalam mencari ilmu, tinggalkan negerimu dan berkelanalah, kelak engkau akan menemukan pengganti orang yang kau tinggalkan, bersusuah payalah, karena sesungguhnya ketinggian derajat kehidupan hanya bisa dicapai dengan kesusahpayahan". 6

Pernyataan tersebut memacu dan mendorong Syekh Nawawi Al-Bantani untuk menggali, mencari, dan memperdalam ilmu agamanya pada usia 15 tahun, dimana pada usia tersebut Syekh Nawawi bersama kedua saudaranya pergi ke Makkah untuk menunaikan ibadah Haji, setelah musim haji usai ia tidak langsung pulang ke Indonesia melainkan tinggal di Mekah untuk memperdalam ilmu Agamanya. ${ }^{7}$ kesempatan ini digunakannya untuk belajar Ilmu Kalam, Bahasa dan Sastra Arab, Ilmu hadits, Tafsir dan terutama belajar ilmu Fiqh. ${ }^{8}$ Dorongan serta ketekunan yang kuat menyebabkan Nawawi bertahan di Mekah untuk menimba ilmu kepada ulama-ulama besar kelahiran Indonesia dan negeri lainnya seperti Mekah, Hejaz, dan daerah-daerah sekitar mekah serta beliau sempat belajar hingga ke Mesir. ${ }^{9}$ Pertama kali beliau belajar di Masjidil Haram Mekah yang ketika itu merupakan satu-

\footnotetext{
${ }^{5}$ Nur Rokhim, Kiai-Kiai Kharismatik dan Fenomenal, (Yogyakarta:IRCisoD,2015), hal.89

${ }^{6}$ Suwito dan Fauzan, Sejarah Pemikiran Para Tokoh Pendidikan,..., hal. 290

${ }^{7}$ Salman Iskandar, 55 Tokoh Muslim Indonesia Paling Berpengaruh,... hal.64

${ }^{8}$ Maragustam, Pemikiran Pendidikan Syekh Nawawi Al-Bantani,..., hal.102

${ }^{9}$ Ibid,. Hal. 102
}

AL-IKHTIBAR (Jurnal Ilmu Pendidikan) Vol. 5 No. 2 Tahun 2018 
satunya pendidikan Islam tertinggi di Mekah. Ditempat ini beliau belajar kepada Syekh Sayyid Akhmad Nakhrawi, Syekh Sayyid Ahmad Dimyati, dan Syekh Ahmad Zaini Dahlan, setelah itu beliau belajar di Madinah pada Syekh Khatib Al-Hambali. ${ }^{10}$ Banyak hal yang ia pelajari dari guru-gurunya ini, mulai dari Ushuluddin, Fiqh, Balaghah, Sampai dengan Mantiq.

Ulama yang cukup mewarnai prinsip keilmuan dan jalan pikiran Syekh Nawawi Al-Bantani adalah Syekh Sayyid Akhmad Nakhrawi dan Syekh Sayyid Ahmad Dimyathi, sebab dua ulama inilah yang mula-mula membimbing Nawawi dalam berbagai disiplin ilmu, membentuk karakternya dengan sikap positif didalam menghadapi goncangan psikologis yang ada dan mengajarkan untuk selalu memegang nilai-nilai Agama dan memantapkan prinsip Aqidah. Tiga tahun lamanya, Nawawi menggali ilmu dari ulama-ulama Mekah, setelah merasa bekal ilmunya cukup, ia kembali ketanah kelahirannya untuk memulai mengamalkan dan mengajarkan ilmu yang dimilikinya kepada umat yang sangat mengharapkan kehadirannya. Akan tetapi karena kondisi tanah air ketika itu masih berada dibawah penjajahan Belanda, dan setiap gerak-gerik ulama diawasi,termasuk kegiatan Syekh Nawawi-Al-Bantani, beliau kembali kembali ke Mekah dan tinggal di perkampungan Syi' 'ib. ${ }^{11}$

Kecerdasan dan ketekunan menghantarkannya menjadi salah satu murid yang terpandang di Masjidil Haram. Ketika Syekh Ahmad Khatib sambas uzhur menjadi imam Masjid, ia ditunjuk untuk menggantikannya. Sejak itulah ia menjadi Imam Masjidil Haram dengan panggilan Syekh Nawawi Al- Bantani Al-Jawi. selain menjadi Imam ia juga mengajar dan menyelenggarakan diskusi ilmiah secara halaqah bagi murid-muridnya yang datang dari berbagai belahan dunia yang berkisar pada

\footnotetext{
${ }^{10}$ Suwito dan Fauzan, Sejarah Pemikiran Para Tokoh Pendidikan,..., hal.290

11 Sudirman Tebba, Mengenal Wajah Islam yang Ramah, (Ciputat Tanggerang Banten:Pustaka Irvan,2007), hal.157
}

AL-IKHTIBAR (Jurnal Ilmu Pendidikan) Vol. 5 No. 2 Tahun 2018 
tahun 1860-1870 yang merupakan tahun dimana ia sudah secara aktif menulis berbagai kitab.

Laporan C. Hurgonje, seorang orientalis pernah mengunjungi Mekah pada tahun 1884-1885 menyebutkan sejak pukul 07.30-12.00, Syekh Nawawi memberikan tiga perkuliahan sesuai dengan kebutuhan jumlah muridnya, sebagian muridnya berasal dari Indonesia, seperti K.H Khalil (Madura), K.H. Hasyim Asy'ari (Jawa Timur), K.H. Raden Asnawi (Jawa Tengah), K.H. Asy'ari (Bawean), K.H. Asnawi (Caringin Labuan Banten), K.H. Tubagus Bakri ( Sempur Purwakarta), serta K.H Arsyad Thawil dari Banten. Mereka inilah yang kemudian menjadi ulama-ulama terkenal.

Syekh Nawawi juga sangat giat dalam menulis buku, ia termasuk penulis yang produktif dalam melahirkan kitab-kitab mengenai berbagai persoalan agama, paling tidak ada 34 karyanya tercatat dalam Dictionary Of Arabic prientea books karya Yusuf. ${ }^{12}$ Beberapa kalangan malah menyebut karyanya-karyanya mencapai lebih dari 100 judul, meliputi berbagai disiplin ilmu, seperti tauhid, ilmu kalam, sejarah, syari'ah, tafsir dan lainya. Diantara buku yang ditulisnya dan mu'tabar adalah tafsir Marah Labid, Atsimar Al-Yaniah fi Ar-Riyadah Al-Badiah, Nurazh Sullam, AlFutubat Al-Madaniyah, Tafsir Al-Munir,Tangih Al-Qoul, Fath majid, Sullam Munajah, Nihayah Zein, Salalim Al-Fudhala, Bidayah Al-Hidayah, Al-Ibriz Al-Dani, Bugyah Al-Awwam, Futhus Samad, dan Al-Aqdhu Tsamin. ${ }^{13}$ Uraian lebih jelas karya-karya syekh nawawi oleh M.Th.Moutsma dan A.J.Wensinch dkk,serta Harun di klasifikasikan kedalam nomor-nomor berikut: ${ }^{14}$

1. Bidang Ilmu Kalam (Teologi Islam), diantaranya: Kitab Fath Al-Majid (1298 H), Tijan Al-darari (1301 H) , Kasyifah Al-Saja (1292 H), Al-Nahjah Al-Jadidah $(1303 \mathrm{H})$, Zari'ah al-Yaqin 'ala Umm al-Barahin $(1317 \mathrm{H})$, Al- Risalah al-

${ }^{12}$ Solihin, Rosihon anwar, Ilmu Tasawuf, (Bandung:Pustaka Setia,2008), hal.267

${ }^{13}$ M Ulul Fahmi, Ulama Besar Indonesia, Biografi dan Karyanya, (Kendal: Pustaka Amanah,2007), hal. 11-12

${ }^{14}$ Maragustam, Pemikiran Pendidikan Syekh Nawawi Al-Bantani,..., hal. 107-108

AL-IKHTIBAR (Jurnal Ilmu Pendidikan) Vol. 5 No. 2 Tahun 2018 
jami'ah Bain Usul al-din wa al-Fiqh wa al-Tasawuf (1292 H), Al- Simar alYani'ah (1299 H), Hilyah al-Sibyan 'ala Fath Al-Rahman (Tanpa Tahun) dan Nur-al-Zulam (1329 H).

2. Bidang Fiqh (hukum Islam), diantaranya: Al-Tausyeh $(1314 \mathrm{H})$,Sulam al-Munajat (1297 H), Nihayah al-Zain (1297 H), Mirqah Al-Su'ud Al-Tasdiq (1292 H), Suluk Al-Jadah (1300 H), Al-Aqd Al-Samin (1300 H), Fath Al-Mujib (1276 H), 'Uqud al-Lujaen fi Bayan Huquq Al-Zaujaen (1297 H), Qutul Habibi Al-Garib (1301 H), dan Kasyifah Al-saja (1292 H). Karya-karya tersebut merujuk Madzhab Syafi'i dimana beliau sebagai pengikutnya.

3. Bidang Akhlak/Tasawuf, perilaku sufinya nampak dalam kezuhudan dan ketawaduanyya. Tarekat yang diikutinya adalah tarekat Qadiriah, karena beliau sangat erat hubunganya dengan Kyai Abdul Karim bin Bukhori bin Ali yang dikenal sebagai tokoh tarekat Al-Qadiriah di Mekah dan sama-sama berasal dari banten. Tulisannya di bidang ini antara lain: Qami' Al-Tugyan 'ala Manzumah Syub al-iman (1296 H), Salailim al-fudala (1315 H), Misbah Al-Zulm 'ala Manhaj al-Atam fi tawbib al-hukm (1314 H), Maraqi al-Ubudiyah (1298 H), dan Syarh ala Manzumah a Al-Syekh Muhammad Al-Dimyati fi al-Tawassul bi Asma' Allah Al-Husna $(1302 \mathrm{H})$.

4. Bidang Tarikh Kelahiran/kehidupan Nabi Muhammad SAW. Seperti: Al-Ibrir AdDani (1292 H), Madarij Al-Su'ud ila Iktisa'il Burud (1296 H), dan Fath Samad $(1292 \mathrm{H})$.

5. Bidang bahasa dan kesusateraan Arab. Misalnya: Fath Gafir Al-Khotihiyah 'ala Al-kawakib Al-Jaliyah Fi Nazm Al-Jurimiyah (1298 H), Al Fusush Al-Yaqutiyah (1299 H), Kasyf Al-Marutiyah (1292 H), dan Luba Al-Bayan (1301 H).

6. Bidang Tafsir - Hadits. Beliau menulis tafsir Murah atau Al-Munir (1305 H) yang terdiri dari dua jilid Tanqih al-Qaul (tanpa Tahun) dalam bidang hadis

Kitab-kitab Syekh Nawawi Al-Bantani banyak di terbitkan di Mesir. Selanjutnya, kitab-kitabnya itu menjadi bagian dari kurikulum pendidikan agama di 
seluruh pesantren di Indonesia, bahkan Malaysia, Filifina, Thailand, dan juga Timur Tengah. Setelah karyanya banyak masuk di Indonesia, wacana keIslaman yang dikembangkan di pesantren mulai berkembang. Sejak 1888, kurikulum pesantren mulai ada perubahan yang mencolok. Jika sebelumnya tidak ditemukan sumber referensi dibidang tafsir,ushul fiqh, dan hadits, sejak saat itu bidang keilmuan tersebut mulai dikaji. Karya-karya Syekh Nawawi memang mendominasi kurikulum pesantren sampai tahun 1990 yang tidak terlepas dari jasa K.H. Hasyim Asy’ari, yang merupakan salah seorang murid Syekh Nawawi yang berasal dari Jombang. Syekh nawawi Al-Bantani wafat dalam Usia 84 Tahun di Syeib 'Ali, sebuah kawasan dipinggiran kota Mekah, pada 25 Syawal 1314 H/1879 M. Ia dimakamkan di ma'la, Arab Saudi, dekat makam istri Rasulullah SAW yang pertama, Ummul Mukminin Khadijah binti Khuwailid r.a.

\section{B. Ide-ide Pemikiran Syekh Nawawi Al-Bantani Dalam dunia Pendidikan Islam}

Pada prinsipnya para ahli sependapat dalam hal membangun ide-ide dasar pendidikan Islam yaitu, Ontologi, pandangan Islam tentang jagad raya, manusia, kehidupan dunia akhirat,dan lingkungan masyarakat muslim, epistimologi yakni pandangan Islam tentang pengetahuan, dan aksiologi yakni pandangan Islam tentang nilai-nilai akhlak. Dalam hal ini kita akan membahas mengenai ide -ide pemikiran pendidikan Syekh Nawawi Al-Bantani, diantaranya:

\section{Eksistensi Alam Semesta}

Menurut Syekh Nawawi Al-Bantani, Tuhan adalah pencipta langit dan bumi dan apa saja diantara keduanya dengan tujuan (hikmah) tertentu baik tujuan keagamaan maupun keduniaan, agar para ilmuan memikirkan, mengetahui dan mengambil-bukti-bukti dari padanya. ${ }^{15}$ Artinya, alam sebagai ciptaan-Nya telah dirancang dengan tujuan-tujuan tertentu, agar manusia mengakui eksistensi Tuhan,

\footnotetext{
${ }^{15}$ Maragustam, Pemikiran Pendidikan Syekh Nawawi Al-Bantani,..., hal.122
}

AL-IKHTIBAR (Jurnal Ilmu Pendidikan) Vol. 5 No. 2 Tahun 2018 
mencari rezki, ilmu dengan memanfaatkan hukum alam serta mencari kebahagiaan hidup dunia dan akhirat.

Bagi Syekh Nawawi, disamping ukuran-ukuran tertentu dari setiap jenis alam ini, sifat alam atau Sunatullah juga berjalan atas dasar hukum kausal. Seperti halnya hakekat reproduksi dalam kehiran anak tidak dapat berhasil tanpa perantaraan bapak.demikian pula hakikat terjadinya sesuatu atau terjadinya reproduksi secara maknawi tidak akan berhasil tanpa adanya pendidik, penunjuk, atau instruktur. ${ }^{16}$ Dengan kata lain, mustahil ada kelahiran atau timbulnya sesuatu secara maknawi tanpa adanya penunjuk atau pendidik atau instruktur.

Syekh Nawawi juga mengatakan, alam ini diciptakan dengan penuh keharmonisan dan keteraturan, penuh kepastian (takdir) dan tetap, bahkan tuhanpun tidak akan mengubah hukum ketetapan (sunatullah) yang diciptakan-Nya. Dengan adanya kepastian dan keteraturan itu maka hukum alam itu berulang dan objektif. ${ }^{17}$

Dengan demikian hakikat alam semesta menurut Syekh Nawawi dapat diringkas menjadi 6 prinsip, yaitu pertama, adanya alam semesta diciptakan Allah dengan kepastian (ukuran-ukuran tertentu). Kedua, hukum alam (sunatullah) itu tidak pernah berubah atau berjalan terus menerus. Ketiga, sifat sunatullah alam ini ialah adanya keterulangan. Keempat, sunatullah itu sifatnya objektif, kelima, bahwa penciptaan alam ini mempunyai hikmah atau tujuan yakni agar dapat dipelajari dan diteliti sehingga bermanfaat dan berguna bagi kehidupan keagamaan dan keduniaan. Keenam, alam semesta ini berjalan atas dasar hukum kausal.

\section{Eksistensi Manusia}

Tuhan menciptakan manusia yang terdiri dari unsur roh dan jasad dengan rumit dan penuh misteri sebanding dengan jati dirinya yang unik, misterius dan tak terduga srta sifat-sifat kompleksnya. Roh dan jasad dua unsur yang tidak bisa dipisah satu dengan yang lainnya, keduanya merupakan satu kesatuan yang saling

\footnotetext{
${ }^{16}$ Ibid, hal.124

${ }^{17}$ Ibid., hal.124
}

AL-IKHTIBAR (Jurnal Ilmu Pendidikan) Vol. 5 No. 2 Tahun 2018 
menyempurnakan. Menurut Syekh Nawawi sewaktu menafsirkan QS.Al-Hijr (15):2829 dan QS.Al-Rahman (55):14, bahwa Allah menciptakan adam AS dari salsal yakni tanah liat kering tanpa dimasak yang bersuara ketika diukir, yang berasal dari tanah lumpur hitam yang basah dan diberi bentuk dengan serupa adam. ${ }^{18}$ Dengan kata lain dapat dijelaskan bahwa Allah satu-satunya pencipta manusia. Penciptaan adam adalah langsung dari ekstra tanah,sedangkan penciptan manusia pasca Adam berasal dari ekstakta tanah secara tidak langsung yakni melalui reproduksi biologis dari pasangan suami istri dan bahan penciptaannya berasal dari ekstrata tanah dan roh.disamping manusia diberi roh manusia juga diberi potensi-potensi yang mengagumkan dan penuh misteri

\section{Potensi-potensi manusia}

Syekh nawawi berpandangan bahwa manusia diciptakan dalam bentuk seimbang dan sempurna. Secara fisik manusia dapat berdiri tegak sempurna dan seimbang serta dilengkapi dengan akal, kemampuan, memahami, memperoleh imu dan memiliki budi pekerti. ${ }^{19}$ Allah menciptakan manusia terdiri dari berbagai unsur yakni dapat bertutur, mendengar, melihat dan bernalar.setiap unsur menyimpan berbagai keajaiban yang tidak dapat dijangkau oleh orang-orang yang mensifatinya. Jadi manusia diberi kemampuan baik yang bersifat biologis maupun yang bersifat psikologis. Penjelasan Syekh Nawawi tersebut pada prinsipnya telah menggambarkan potensi-potensi manusia yakni potensi fisik dan psikis.

Bergerak dari pendapat Syekh Nawawi maka dari sinilah potensi - potensi tersebut harus dikembangkan karena Potensi-potensi fisiologis dan psikologis manusia tidaklah cukup jika hanya mengandalkan perjanjian primordial dengan Tuhan. Potensi-potensi itu harus dikembangkan melalui pedidikan. Karena tanpa ilmu maka manusia tidak akan mampu mengemban amanah khalifah dan

\footnotetext{
${ }^{18}$ Ibid., hal.126-127

${ }^{19}$ Ibid,. hal.128
}

AL-IKHTIBAR (Jurnal Ilmu Pendidikan) Vol. 5 No. 2 Tahun 2018 
melaksanakan ubbudiyah yang merupakan tanggung jawab manusia untuk menunaikannya.

4. Prinsip-prinsip aktivitas pendidikan Islam

Hakikat pendidikan dan pengajaran dalam Islam menurut syekh Nawawi mencakup term ta'lim, tarbiyah dan ta'dib. Pendidikan mencakup transfer of knowledge, transfer of value, transfer of methodology, dan transformasi. Pendidikan mencakup jasmani (praktik/amal), intelektual, mental/spiritual dan berjalan sepanjang hidup dan integral. ${ }^{20}$

Sifat-sifat pendidikan yang dikemukakan oleh para ahli pendidikan Islam termasuk Syekh Nawawi sangat ketat. Hal ini karena peranan guru dalam Islam tidak sekedar ahli ilmu, nilai dan metode, tetapi juga transformasi (membentuk kepribadian peserta didik). Di samping itu diyakini bahwa para pendidik menempati posisi ulama sebagai pewaris para nabi, sehingga pendidik harus dapat menjadi teladan bagi peserta didiknya.

\section{Tujuan pendidikan}

Menurut syekh Nawawi tujuan memperoleh ilmu atau tujuan pendidikan ialah mardatillah dan memperoleh kehidupan ukhrawiyah, membrantas kebodohan, memajukan Islam, melestarikan Islam dengan kaidah-kaidah ilmu serta sebagai perwujudan dari rasa syukur karena diberi akal dan tubuh yang sehat. Kewajiban bersyukur mencakup aspek keilmuan (ranah kognitif), aspek rasa senang (ranah afektif), dan menggunakan nikmat Tuhan sesuai dengan permintaan pemberi nikmat yakni Allah (ranah psikomotor dan spiritual). ${ }^{21}$ Untuk mencapai tujuan pendidikan tersebut memerlukan pemikiran tentang muatan pendidikan Islam. Dari berbagai pernyataan Syekh Nawawi, hal utama yang diberikan dalam proses pendidikan adalah masalah ilmu-ilmu keagamaan yang wajib personal. Sedangkan yang paling utama dari kewajiban personal itu ialah iman tauhid. ${ }^{22}$

\footnotetext{
${ }^{20}$ Ibid,. hal. 2-3

${ }^{21}$ Ibid,.hal. 258-259

${ }^{22}$ Ibid,.hal.259
}

AL-IKHTIBAR (Jurnal Ilmu Pendidikan) Vol. 5 No. 2 Tahun 2018 
Kurikulum pendidikan Islam yang tidak didasarkan pada tauhid akan melahirkan manusia yang serba tergantung kepada makhluk, dan akan melahirkan manusia-manusia yang menyimpan tuhan-tuhan kecil selain Allah serta melahirkan musyrik-musyrik kecil pula. Dalam kurikulum pendidikan Islam, Syekh Nawawi menekankan ilmu muqaddimaat karena ilmu-ilmu keagamaan itu berbahasa Arab dan peserta didik berkewajiban mempelajarinya.

Pada masa sekarang ini bahasa sangat dipentingkan dalam kurikulum pendidikan Islam. Bahkan kelemahan-kelemahan sekolah-sekolah keagamaan sekarang ini ialah kelemahan penguasaan bahasa. Hal ini sependapat dengan pendapat tokoh pendidikan Islam kontemporer, karena di samping menganggap penting pengetahuan-pengetahuan yang diperoleh (acquired) melalui akal juga mementingkan pengetahuan melalui wahyu (perennial). Sebab wahyu, al-Qur'an dan Sunnah ini tertulis dalam bahasa Arab. Maka keahlian bahasa Arab, terutama yang berkenaan dengan tuntutan dasar Islam seperti ibadat sembahyang dan lain-lain haruslah dikuasai oleh murid-murid dari tingkat dasar. ${ }^{23}$

Peserta didik sebagai makhluk educandum dan educandus menurut Syekh Nawawi sangat memperhatikan lingkungan kebudayaan termasuk pendidikan dan sosialnya. Kehidupan peserta didik berada dalam suatu kontrak sosial. Eksistensi peserta didik berada dalam interdependensi baik secara sosial maupun lingkungan kebudayaan. Pengaruh lingkungan luar terhadap peserta didik sangat signifikan. Untuk itu Syekh Nawawi membuat etika peserta didik, agar lebih selektif dalam memilih lingkungan sosial dan teman dalam pergaulan. ${ }^{24}$

Beberapa etika peserta didik terhadap ilmu menurut Syekh Nawawi di antaranya: $:^{25}$

\footnotetext{
${ }^{23}$ Langgulung, Hasan. Manusia dan Peradaban, Suatu Analisa Psikologi dan Pendidikan. (Jakarta: Al-Husna Zikra, 1995), hal.203

${ }^{24}$ Maragustam, Pemikiran Pendidikan Syekh Nawawi Al-Bantani,..., hal 262

${ }^{25} \mathrm{Ibid}, .$. hal.81-82
}

AL-IKHTIBAR (Jurnal Ilmu Pendidikan) Vol. 5 No. 2 Tahun 2018 
1. Membersihkan hatinya dari kotoran-kotoran dan dosa untuk menerima ilmu, memeliharanya dan mendapatkan hasilnya.

2. Selalu mencari ridha gurunya sekalipun berbeda pendapat dengannya, tidak boleh mengumpat atau memfitnahnya, dan tidak boleh mencari-cari kesalahannya secara sembunyi-sembunyi.

3. Ia seharusnya tamak dalam belajar, disiplin dalam seluruh waktunya, malam, siang, berada di tempat dan waktu musyafir.

4. Bersabar atas perilaku guru dan kejahatan akhlaknya.

5. Memperhatikan kesahehan pelajaran yang ia dapatkan secara benar dan meyakinkan dari gurunya.

Adapun prinsip-prinsip metodik dalam pendidikan Islam menurut pendapat Syekh Nawawi, sebagai berikut: ${ }^{26}$

1. Menyajikan mata pelajaran secara jelas dimulai dari yang mudah, yang konkrit yang dapat ditangkap oleh akal pikiran peserta didik, baru kemudian secara bertahap dibawa kepada yang lebih sulit dan abstrak.

2. Dalam penyampaian materi, pendidik harus melihat keadaan peserta didiknya terutama dalam hal kemampuan dan tipologinya.

3. Menggunakan metode mengajar sesuai dengan keadaan peserta didiknya.

4. Guru dalam menyampaikan materi tidak menambah pelajaran sebelum pelajaran yang terdahulu dipahami peserta didiknya karena hal itu akan membuat peserta didik menjadi malas.

5. Prinsip pengulangan (tikrar) dalam pengajaran.

Selain itu, Syekh Nawawi juga mengemukakan bahwa etika relasi guru dan murid juga memberikan etika bersama antara guru dan murid. Yaitu keduanya tidak boleh melanggar kewajiban, fungsi dan kedudukan masing-masing pihak, seperti adanya penyakit ringan dan semisalnya yang dengannya ia bekerja atau sibuk. Dan ia meminta sembuh dengan ilmu dan tidak boleh bertanya kepada seseorang dengan

${ }^{26}$ Ibid,.. hal.263

AL-IKHTIBAR (Jurnal Ilmu Pendidikan) Vol. 5 No. 2 Tahun 2018 
cara menekan dan melemahkan. Bagi penanya yang demikian tidak berhak mendapatkan jawaban. ${ }^{27}$

Salah satu lembaga pendidikan yang penting ialah pendidikan keluarga. Keluarga memiliki dampak yang besar dalam pembentukan perilaku dan pengembangan vitalitas dan ketenangan dalam keluarga. Melalui keluarga, anak-anak mendapatkan bahasa, nilai dan norma serta kecenderungan mereka. ${ }^{28}$ Ulama-ulama Islam klasik menekankan pentingnya peranan pendidikan bagi keluarga dan pentingnya keluarga memegang peranan itu terutama pada usia kanak-kanak. Hal itu berdasar pengalaman-pengalaman mereka sendiri, juga pengalaman dan perhatian orang-orang sebelumnya. selain itu, nash-nash al-Qur'an, sunnah dan bekas-bekas peninggalan Assalaf-Saleh yang banyak menekankan pentingnya peranan pendidikan bagi keluarga. ${ }^{29}$ Syekh Nawawi menambahkan bahwa tanggung jawab pendidikan dalam keluarga tidak hanya mengirimkan anak kepada guru, tetapi juga tentang biaya pendidikannya. Apabila keluarga tidak mampu, maka biaya pendidikan dibebankan kepada pemerintah, sedangkan apabila pemerintah tidak mampu maka tanggung jawabnya dibebankan kepada orang-orang yang mampu. ${ }^{30}$

C. Relevansi Pemikiran Pendidikan Syekh Nawawi terhadap Dunia Modern

Posisi Syekh Nawawi dalam peta pemikiran pendidikan Islam lebih dekat kepada perenialis-enensialis madzhabi. Karena dari sisi parameternya, beliau dalam memperkuat uraian pemikiran pendidikan banyak mengemukakan nash, dan pemikiran salaf asshalih masa abad klasik dan pertengahan. Disamping itu, ia mempertahankan dan melestarikan pemikiran para pendahulunya yang dianggap relevan dengan situasi sekarang. Dikatakan 'relevan' karena menurut syekh Nawawi, hasil pemikiran itu selalu terbuka untuk dikritik bahkan ditinggalkan. Dari sisi ciri-

${ }^{27}$ Ibid,.. hal.82-83

${ }^{28}$ Ibid,.. hal. 264

${ }^{29}$ Langgulung, Hasan. Manusia dan Peradaban, Suatu Analisa Psikologi dan Pendidikan., hal.361.

${ }^{30}$ Maragustam, Pemikiran Pendidikan Syekh Nawawi Al-Bantani,...,265

AL-IKHTIBAR (Jurnal Ilmu Pendidikan) Vol. 5 No. 2 Tahun 2018 
ciri pemikirannya, menekankan pada pemberian syarh dan hasyiyah terhadap pemikiran pendahulunya dan berani mengkritisi atau mengembangkan pemikiran pendahulunya untuk merekonstruksi pemikirannya sendiri. Dengan adanya pengembangan bahkan berbeda dengan yang di-syarh dan di-hasyiyah, menempatkan beliau mempunyai kemampuan yang orisinial di bidang pendidikan Islam. ${ }^{31}$

Dalam menggambarkan ide-ide dasar pendidikan, kecenderungan syekh Nawawi terhadap nuansa agamisnya lebih dominan sehingga aspek lain menjadi kurang dominan. Penafsiran realitas berpangkal pada agama, maka pendidikan pun dijadikannya sebagai instrumen untuk mencapai tujuan-tujuan keagamaan. ${ }^{32}$ Pemikiran Syekh Nawawi tersebut tentu memiliki dampak positif dan dampak negatif edukatifnya. Dampak positifnya edukatif adalah rasa tanggung jawab yang sangat kuat telah menghujam pada pemikiran pendidikannya, dan mengukuhkan rasa tanggung jawab moral. Penghargaannya terhadap persoalan pendidikan Islam sangat tinggi, bahkan menilainya sebagai wujud tanggung jawab keagamaan yang sangat luhur. Tugas mengajar dan belajar tidak sekadar sebagai tugas-tugas profesi kerja dan tugas-tugas kemanusiaan tetapi lebih jauh dari itu yakni sebagai tuntutan kewajiban agama. Tanggung jawab dan kewajiban agama sebagai titik sentral baik dalam kontruksi tataran konsep maupun tataran aplikasi pendidikan. Atau dengan kata lain jika tuntutan tidak sejalan dengan tuntutan keagamaan, maka yang harus didahulukan ialah tuntutan keagamaan. ${ }^{33}$

Adapun dampak negatif edukatifnya.Syekh Nawawi menjadi term al-'ilm yang dalam nash bersifat mutlak, bersifat muqayyad (terbatas), hanya pada ilmu keagamaan, dan kecenderungan pencapaian spiritual yang lebih menonjol. Mendorong pemikiran pendidikan Islam ke arah pengabaian urusan dunia dengan segala kemanfaatan dan amal usaha yang sebenarnya boleh dinikmati. Oleh karena itu

\footnotetext{
${ }^{31}$ Maragustamsiregar.www.wordpress.com.2010

${ }^{32}$ Maragustam, Pemikiran Pendidikan Syekh Nawawi Al-Bantani,...,266

${ }^{33}$ Ibid,. Hal. 267-268
}

AL-IKHTIBAR (Jurnal Ilmu Pendidikan) Vol. 5 No. 2 Tahun 2018 
pengabaian urusan dunia, maka ilmu-ilmu yang bersifat keduniaan dikuasai oleh non muslim dan menjadi lemahnya pelaksanakan amar makruf nahi munkar dalam reformasi dan transformasi sosial yang bermoral. Padahal penguasaan dunia sebagai sarana pendakian kebahagiaan di akhirat. ${ }^{34}$

Ide-ide Syekh Nawawi tentang etika pendidik dan peserta didik dan etika bersama terdapat implikasi bahwa tokoh ini melihat peserta didik masih memerlukan tuntunan dan bimbingan. Peserta didik belum bisa lepas dari pendidik, ia tetap dalam bimbingan dan pengawasan pendidik. Peserta didik merupakan orang yang belum dewasa, namun memiliki potensi yang luar biasa. Untuk itu pendidik berperan besar untuk mengaktualisasikannya. ${ }^{35}$

Dari berbagai keterangan Syekh Nawawi tentang kurikulum pengajaran, terdapat implikasi bahwa memandang pengetahuan itu berdasarkan dari sudut pandang aplikatif dari norma-norma agama bukan dari sudut substansi ilmu tersebut. Dengan kata lain dasar atau hal yang esensial didahulukan kemudian disusul dengan materi lain. Mendahulukan matan kitab dari pada syarh dalam pendidikan. Mendahulukan kewajiban personal kemudian disusul dengan kewajiban komunal dan sunnah komunal. ${ }^{36}$

Akhirnya, pengkaji melihat bahwa pemikiran Syekh Nawawi al-Bantani dalam dunia pendidikan Islam yang di gagasnya tetap relevan untuk di aktualisasikan dalam dunia modern dan masyarakat Indonesia yang religious dan multicultural. Seperti, prinsip-prinsip pendidikan yang mengacu kepada tauhid illahiyyah dan reformasi sosial. Sifat dasar manusia dan proses perkembangannya ialah fitrah tauhid-dualis-interaktif berpengaruh dalam proses pembelajaran. Dana pendidikan yang dibebankan kepada orang-orang yang mampu di kalangan umat Islam termasuk prinsip yang dapat direfleksikan dalam dunia pendidikan dewasa ini.

\footnotetext{
${ }^{34}$ Maragustamsiregar.www.wordpress.com.2010

${ }^{35}$ Maragustam, Pemikiran Pendidikan Syekh Nawawi Al-Bantani,..hal.269

${ }^{36} \mathrm{Ibid}, . .$. hal .270
}

AL-IKHTIBAR (Jurnal Ilmu Pendidikan) Vol. 5 No. 2 Tahun 2018 


\section{PENUTUP}

Syekh Nawawi al-Bantani adalah seorang ulama dan intelektual yang legendaris. Melalui karya-karyanya yang mendunia dalam berbagai bidang, menjadikannya panutan oleh banyak pemburu ilmu pengetahuan. Selain ilmu-ilmu agama, beliau juga ahli dalam bidang pendidikan. Karya-karyanya sangat luar biasa, karena banyak memiliki kandungan syarh yang padat tentang karya-karya ulama terdahulu dan telah di modifikasi sehingga memudahkan pembacanya. Pemikiran pendidikannya sangat komulatif dari mulai ide dasar, nilai-nilai, sampai panduan aktivitas pembelajaran dalam Islam. Dasarnya adalah kajiannya dari para pemikir klasik, pertengahan dan modern yang kemudian di integrasikan dengan buah pemikirannya sendiri. Menjadikan hasil dari pemikirannya sangatlah realitas dan dapat memenuhi kebutuhan para praktisi pendidikan Islam. Ditambah dengan pondasi pengetahuan keagamaan serta pemahaman hukum-hukum Islam yang mendalam, serta pengaruh para guru sehingga membentuk karakter yang matang. Pemikirannya dalam pendidikan Islam sebagian besar masih relevan untuk di terapkan dalam kehidupan dunia modern.

\section{DAFTAR PUSTAKA}

Fauzan dan Suwito, Sejarah Pemikiran Para Tokoh Pendidikan, Bandung: Angkasa, 2003

Langgulung, Hasan. Manusia dan Peradaban, Suatu Analisa Psikologi dan Pendidikan. Jakarta: Al-Husna Zikra, 1995

Maragustam, Pemikiran Pendidikan Syekh Nawawi Al-Bantani, Yogyakarta: Data Media, 2007

Maragustamsiregar.www.wordpress.com.2010

Muhammad Ulul Fahmi, Ulama Besar Indonesia, Biaografi dan Karyanya, Kendal: Pustaka Amanah, 2007

Rosihon anwar Solihin, , Ilmu Tasawuf, Bandung:Pustaka Setia,2008 
Rokhim Nur, Kiai-Kiai Kharismatik dan Fenomenal, Yogyakarta:IRCisoD, 2015

Iskandar Salman, 55 Tokoh Muslim Indonesia Paling Berpengaruh, Solo: Tiga Serangkai, 2011

Tebba Sudirman, Mengenal Wajah Islam yang Ramah, Ciputat Tanggerang Banten:Pustaka Irvan, 2007 